\title{
Analysis of multiscale radiometric data collected during the Cold Land Processes Experiment-1 (CLPX-1)
}

\author{
M. Tedesco, ${ }^{1}$ E. J. Kim, ${ }^{2}$ A. Gasiewski, ${ }^{3}$ Marian Klein, ${ }^{3}$ and B. Stankov ${ }^{3}$ \\ Received 16 March 2005; revised 6 June 2005; accepted 1 July 2005; published 17 September 2005.
}

[1] Histograms of brightness temperatures collected at 18.7 and $37 \mathrm{GHz}$ over the Fraser and North Park MesoScale Areas during the Cold Land Processes Experiment by the NOAA Polarimetric Scanning Radiometer (PSR/A) airborne sensor are modelled by a log-normal distribution (Fraser, forested area) and by a bi-modal distribution (North Park, patchy-snow, non-forested area). The brightness temperatures are re-sampled over a range of resolutions to study the effects of sensor resolution on the shape of the distribution, on the values of the average brightness temperatures and standard deviations. The histograms become more uniform and the spatial information in the initial distribution is lost for a resolution larger than $5000 \mathrm{~m}$, in both areas. The values of brightness temperatures obtained by re-sampling the PSR-A data at $25 \mathrm{~km}$ resolution are consistent with those recorded by the Advanced Microwave Scanning Radiometer (AMSR-E) and Special Sensor Microwave/Imager (SSM/I) satellite radiometers at similar resolutions. Citation: Tedesco, M., E. J. Kim, A. Gasiewski, M. Klein, and B. Stankov (2005), Analysis of multiscale radiometric data collected during the Cold Land Processes Experiment-1 (CLPX-1), Geophys. Res. Lett., 32, L18501, doi:10.1029/2005GL023006.

\section{Introduction}

[2] Snow represents a fundamental component of the Earth's water cycle, covering more than the half of the northern hemisphere land surface (around 60\%) in mid winter. Over $30 \%$ of Earth's total land surface is covered by seasonal snow [Robinson et al., 1993]. Microwaves are sensitive to snow parameters [i.e., Macelloni et al., 2001; Tedesco, 2003], which can be estimated using algorithms based on passive microwave remote sensing observations [i.e., Hallikainen and Jolma, 1992; Foster et al., 1997; Tait, 1998; Kelly et al., 2003; Tedesco et al., 2004a]. The microwave signal of snow covered soil is sensitive to the phase of water, mean grain size, fractional volume and snow depth. In the case of dry snow (the cases considered for this study) the mechanism dominating the microwave signal is the volumetric scattering due to the scatterers (ice particles). The retrieval of snow parameters from microwave remotelysensed data has many advantages, but a discrepancy exists

\footnotetext{
${ }^{1}$ Goddard Earth Science Technology Center, UMBC/NASA Goddard Space Flight Center, Greenbelt, Maryland, USA.

${ }^{2}$ Instrumentation Sciences Branch, NASA Goddard Space Flight Center, Greenbelt, Maryland, USA. USA.

${ }^{3}$ NOAA Environmental Technology Laboratory, Boulder, Colorado,
}

Copyright 2005 by the American Geophysical Union. 0094-8276/05/2005GL023006 between the small scale at which many snow parameters are measured and understood and the large-scale footprints of current microwave satellite sensors $\left(25 \times 25 \mathrm{~km}^{2}\right)$, as in example discussed in [Derksen et al., 2005; Jackson, 2001; Drusch et al., 1999; Famiglietti et al., 1999]. At large scales, the heterogeneity of the terrain within the pixel is a limiting factor for the use of forward radiative transfer models to reproduce the observed brightness temperatures using point scale or area-aggregated snow properties.

[3] In this study, we analyze the brightness temperatures at 18.7 and $37 \mathrm{GHz}$ collected in Colorado, central Rocky Mountain of the western United States, by an airborne passive microwave imager, the NOAA Polarimetric Scanning Radiometer (PSR/A) and by the Advanced Microwave Scanning Radiometer (AMSR-E) and Special Sensor Microwave/Imager (SSM/I) satellite radiometers during the third Intensive Observation Period (IOP3, dry snow, February 19-25, 2003) of the NASA Cold Land Processes Experiment-1 (CLPX-1) (http://www.nohrsc.nws.gov/ cline/ clpx.html). In particular, we concentrate on the data collected over the Fraser and North Park Meso-Scale Areas (MSAs). The brightness temperatures collected by the airborne and space-borne instruments are re-sampled, respectively, at $500 \mathrm{~m}(\mathrm{PSR} / \mathrm{A})$ and $25 \mathrm{~km}$ (SSM/I and AMSR-E) resolutions. Histograms of the brightness temperatures collected by the PSR/A over the Fraser and North Park MSAs are plotted at different resolutions, from $500 \mathrm{~m}$ to $25 \mathrm{~km}$. Histograms at $500 \mathrm{~m}$ resolution are used to identify distribution functions for both MSAs. The effect of a coarser resolution on the shape of the distribution is studied. At $25 \mathrm{~km}$ resolution, microwave brightnesses are also compared with those from the SSM/I and AMSR-E satellite radiometers.

\section{The Study Areas and the Radiometric Data}

[4] The largest study area is the large regional study area (LRSA, $375 \times 375 \mathrm{Km}^{2}$ ) and it is located in northern Colorado and southern Wyoming, U.S.A. The small regional study area (SRSA) is located in north-central Colorado $\left(105^{\circ}-107.5^{\circ} \mathrm{W}, 39.5^{\circ}-41^{\circ} \mathrm{N}\right)$, and it is approximately $215-\mathrm{km} \times 170-\mathrm{km}$. Nested within the SRSA are the Fraser and North Park Meso-cell Study Areas (MSAs, $25-\mathrm{km} \times 25-\mathrm{km})$, used for airborne data collection. The Fraser MSA is a topographically complex area with a mean elevation of $3066 \mathrm{~m}$, a range of nearly $1400 \mathrm{~m}$ and a maximum elevation of $3962 \mathrm{~m}$. The highest-elevation areas in the south of the MSA are predominantly alpine tundra or bare rock. The mountain areas are dominated by dense coniferous forests. The North Park MSA has a mean elevation of $2499 \mathrm{~m}$. Most of the vegetation is sage-grassland, with willow along riparian areas. Snow- 


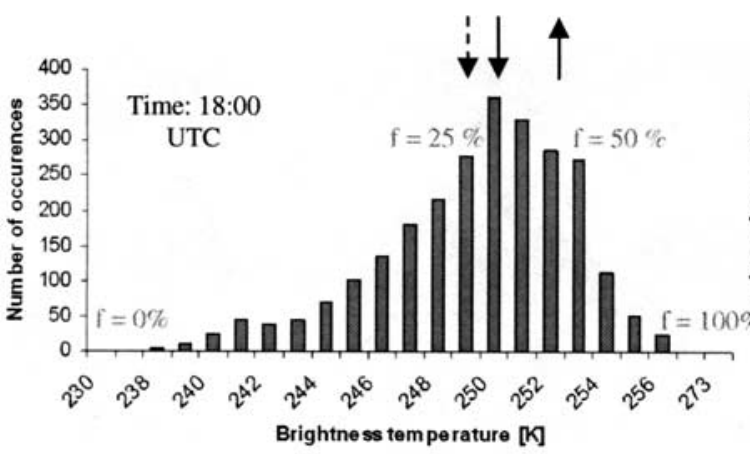

(a)

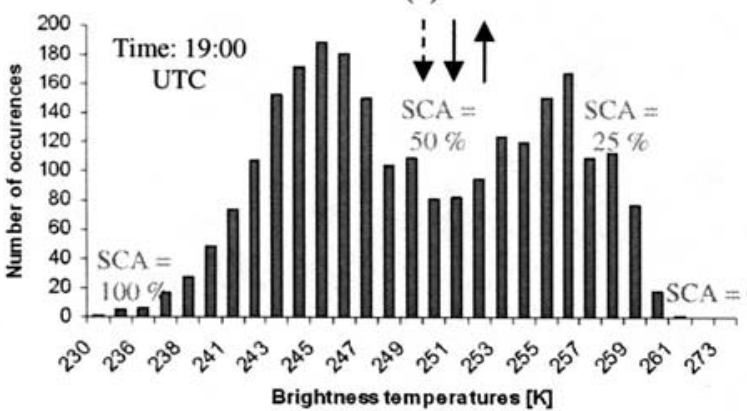

(c)

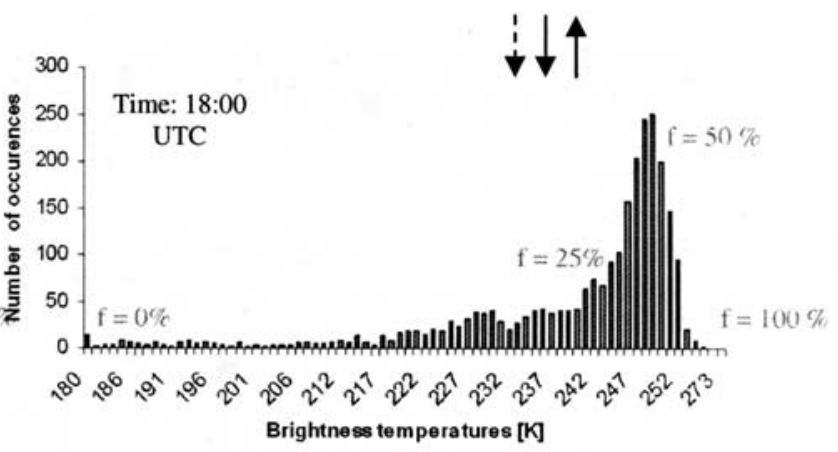

(b)

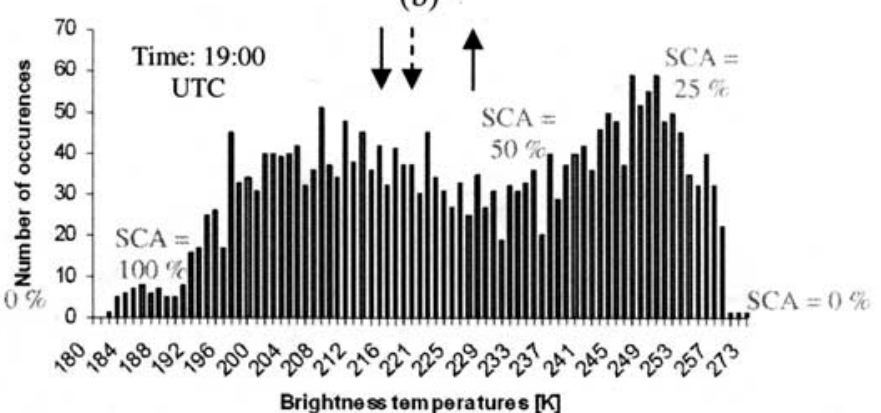

(d)

Figure 1. Histograms of PSR/A brightness temperatures (vertical polarization) at (left) $18.7 \mathrm{GHz}$ and (right) $37 \mathrm{GHz}$ for the (a,b) Fraser and (c,d) North Park MSAs. The brightness temperatures observed by the AMSR-E (solid arrow) and SSM/ I (dotted arrow) are also reported. Upward arrows indicate satellite observations during ascending orbits while downward arrows indicate observations during descending orbits. The values of average brightness temperatures for selected values of forest cover fraction and snow covered area are also indicated.

packs in this area tend to be shallow, and are typical of prairie and arctic- and alpine- tundra snow covers. Further information about the CLPX study areas can be found at http://www. nohrsc.nws.gov/ cline/clpx.html.

[5] Brightness temperatures at fine resolution were collected by means of the NOAA Polarimetric Scanning Radiometer (PSR/A) [Stankov and Gasiewski, 2004], an airborne multiband conical-scanned imaging radiometer system [e.g., Piepmeier and Gasiewski, 1996]. PSR/A includes a single scanhead that provides imagery at most of the AMSR-E imaging bands, with an observation angle of $53^{\circ}$ with respect to nadir. The exact size of the surface footprint is a function of the terrain elevation as the aircraft altitude above sea level was almost constant during the flights. At high frequencies ( 37 and $89 \mathrm{GHz}$ ), the size of the surface footprint ranges between 65 and 229 meters while at $18.7 \mathrm{GHz}$ it ranges between 215 and 749 meters. As the $\mathrm{PSR} / \mathrm{A}$ is a conical-scanned radiometer, the shape of the footprint on the ground depends on the relative orientation of the scene to the $53^{\circ}$ half-cone angle. However, the data collected by the PSR/A used in this study were georegistered according to terrain height and re-sampled to obtain square pixels with a resolution of $500 \mathrm{~m}$, at all frequencies. This value is selected because it is the minimum value which guarantees complete coverage of the observed areas using a square pixel.

[6] Calibrated and geo-located satellite brightness temperatures, acquired over the LRSA using the SSM/I and AMSR-E radiometers were obtained from the National Snow and Ice Data Center (NSIDC) [Brodzik, 2003a, 2003b]. We consider both ascending and descending orbit data, in order to assure the highest number of available observations.

\section{Results and Discussion}

[7] Figure 1 shows the histograms of the brightness temperatures (vertical polarization) collected by the PSR/ A over the Fraser (Figures 1a and 1b) and North Park MSAs (Figures 1c and 1d) re-sampled at $500 \mathrm{~m}$ resolution on February 23, 2003 at 18.7 and $37 \mathrm{GHz}$ (vertical polarization). The values of the brightness temperatures observed by the SSM/I and AMSR-E radiometers are also depicted with arrows (continuous lines for AMSR-E and dotted for SSM/I). Upward arrows indicate satellite observations during ascending orbits while downward arrows indicate observations during descending orbits. In the figure, the average $\mathrm{Tb}$ for different forest fractions and snow covered areas are also reported.

[8] The histograms of the brightnesses collected at the Fraser MSA show a single peak for high values of the brightness temperature, at both 18.7 and $37 \mathrm{GHz}$. The distribution of the brightness temperatures can be modeled using a log-normal distribution, negatively skewed. When radiometric data were acquired, the Fraser MSA was covered by snow with an average snow depth around $1 \mathrm{~m}$ and maxima around 2 meters. The effect of the trees on the histograms is mostly responsible for the shape of the histograms. A comparative analysis between the brightness temperatures and the forest cover fraction derived from MODIS data and Land Use Land Cover (LULC) data was carried out by Tedesco et al. [2004b]. The results show that 
Table 1. Average Values, Peak Values and Standard Deviations for the Brightness Temperatures Collected at the Fraser MSA at Different Re-sampled Resolutions ${ }^{\mathrm{a}}$

\begin{tabular}{|c|c|c|c|c|}
\hline \multirow{2}{*}{$\begin{array}{c}\text { Resolution, m } \\
\text { (Number of pixels) }\end{array}$} & \multicolumn{2}{|c|}{$18.7 \mathrm{GHz}$ Average $=249.3 \mathrm{~K}$} & \multicolumn{2}{|c|}{$37 \mathrm{GHz}$ Average $=240.1 \mathrm{~K}$} \\
\hline & Peak Values, K & Std. Dev., K & Peak Values, K & Std. Dev., K \\
\hline $500(2500)$ & 250 & 6.2 & 249 & 21.9 \\
\hline $1000(625)$ & 252.1 & 5.1 & 248.2 & 17.5 \\
\hline $2500(100)$ & 250.1 & 4.7 & $245 / 249$ & 11 \\
\hline $5000(25)$ & 250.3 & 2.7 & 245.6 & 8.1 \\
\hline $12500(4)$ & n.a. & 1.9 & n.a. & 3.1 \\
\hline \multirow[t]{2}{*}{$25000(1)$} & n.a. & n.a. & n.a. & n.a. \\
\hline & \multicolumn{4}{|c|}{ Satellite Brightness Temperatures, K } \\
\hline$\underline{\text { Satellite Radiometers }}$ & \multicolumn{2}{|c|}{$18.7 \mathrm{GHz}$ Average $=249.3 \mathrm{~K}$} & \multicolumn{2}{|c|}{$37 \mathrm{GHz}$ Average $=240.1 \mathrm{~K}$} \\
\hline AMSR-E D & \multicolumn{2}{|c|}{250.6} & \multicolumn{2}{|c|}{240.4} \\
\hline$A M S R-E A$ & \multicolumn{2}{|c|}{252.8} & \multicolumn{2}{|c|}{242.6} \\
\hline$S S M / I D$ & \multicolumn{2}{|c|}{249.5} & \multicolumn{2}{|c|}{232.2} \\
\hline
\end{tabular}

${ }^{\text {a } T h e ~ v a l u e s ~ o f ~ b r i g h t n e s s ~ t e m p e r a t u r e s ~ o b s e r v e d ~ f r o m ~ A M S R-E ~ a n d ~ S S M / I ~ s a t e l l i t e ~ r a d i o m e t e r s ~ a r e ~ a l s o ~ r e p o r t e d . ~}$

high values of brightness temperatures correspond to high values of forest density. At $18.7 \mathrm{GHz}$ the tail of the distribution is not as long as at $37 \mathrm{GHz}$. This can be explained considering that, in general, the values of brightness temperature at $18.7 \mathrm{GHz}$ are influenced by the soil underlying the snowpack and are higher than those at $37 \mathrm{GHz}$, which are more sensitive to the attenuating influence of the snowpack (lower brightness temperatures).

[9] The distribution of the brightness temperatures collected at the North Park MSA is best modeled using a bimodal distribution. At the time of the data acquisition, the MSA was partially covered by snow with an average snow depth around $20 \mathrm{~cm}$ and a maximum snow depth around $45 \mathrm{~cm}$. The areas with snow are responsible for the low values where the snow-free areas for the high values of brightness temperatures. This is confirmed by comparing the brightness temperatures collected by the PSR/A using snow covered area derived from Moderate Resolution Imaging Spectroradiometer (MODIS). For the data collected at the Fraser MSA, the $37 \mathrm{GHz}$ brightness temperatures appear to be noisier than those collected at $18.7 \mathrm{GHz}$. Although space limitations prevents showing the additional data, the results reported here for the vertical polarization can be extended to the horizontal polarization case for both Fraser and North Park MSAs, at all frequencies.

[10] We next re-sample the PSR/A data at successively coarser resolutions and plot the corresponding histograms.
Our goal is to understand at what spatial scale the histograms can still be described by the initial distribution. We consider five different resolutions for our analysis: 1000 , 2500, 5000, 12500 and $25000 \mathrm{~m}$. In the case of the Fraser MSA, the values of the peaks, the average values and standard deviations are reported in Table 1. As stated earlier, at $500 \mathrm{~m}$ resolution the histograms of the brightness temperatures can be modeled using a log-normal distribution, negatively skewed $\left(\mathrm{R}^{2}=0.92\right)$. Our analysis points out that this is still possible at a resolution of $1000 \mathrm{~m}\left(\mathrm{R}^{2}=0.76\right)$. However, at a resolution of 2500 meters, two values of brightness temperatures at $37 \mathrm{GHz}$ show the same number of occurrences, instead of a single peak. As the resolution gets coarser, the histograms become increasingly uniform, the standard deviation decreases and the brightness temperatures concentrate around a value close to the average. This happens when the resolution reaches approximately $5000 \mathrm{~m}$. In the case of the North Park MSA, the histograms of the brightness temperatures at $500 \mathrm{~m}$ resolution can be modeled using a bi-modal distribution $\left(\mathrm{R}^{2}=0.91\right)$. In this case the values of the peaks, the average values and standard deviations are reported in Table 2. This is still true at $1000 \mathrm{~m}$ resolution $\left(\mathrm{R}^{2}=0.65\right)$. At 2500 resolution, two peaks are still observable with the remaining brightness temperatures showing the same number of occurrences. However, the peak is made of two distinct values, which are very close at $18.7 \mathrm{GHz}$, but they differ by about $10 \mathrm{~K}$ at $37 \mathrm{GHz}$. Also in this case, for

Table 2. Average Values, Peak Values and Standard Deviations for the Brightness Temperatures Collected at the North Park MSA at Different Re-sampled Resolutions ${ }^{\mathrm{a}}$

\begin{tabular}{|c|c|c|c|c|}
\hline \multirow{2}{*}{$\begin{array}{c}\text { Resolution, m } \\
\text { (Number of pixels) }\end{array}$} & \multicolumn{2}{|c|}{$18.7 \mathrm{GHz}$ Average $=250.7 \mathrm{~K}$} & \multicolumn{2}{|c|}{$37 \mathrm{GHz}$ Average $=224.7 \mathrm{~K}$} \\
\hline & Peak Values, K & Std. Dev., K & Peak Values, $\mathrm{K}$ & Std. Dev., K \\
\hline $500(2500)$ & $249,258.7$ & 7.9 & $208,250.2$ & 25 \\
\hline $1000(625)$ & $245.1,258.3$ & 7 & $210.2,245.7$ & 25.5 \\
\hline $2500(100)$ & $247,257 / 259$ & 7.7 & $205.1,240 / 250$ & 18.5 \\
\hline $5000(25)$ & n.a., 258.4 & 8.34 & n.a., n.a. & 16.9 \\
\hline $12500(4)$ & n.a., n.a & 9 & n.a., n.a & 18.8 \\
\hline \multirow[t]{2}{*}{$25000(1)$} & n.a, n.a. & n.a. & n.a, n.a. & n.a. \\
\hline & \multicolumn{4}{|c|}{ Satellite Brightness Temperatures, K } \\
\hline Satellite Radiometers & \multicolumn{2}{|c|}{$18.7 \mathrm{GHz}$ Average $=250.7 \mathrm{~K}$} & \multicolumn{2}{|c|}{$37 \mathrm{GHz}$ Average $=224.7 \mathrm{~K}$} \\
\hline AMSR-E D & \multicolumn{2}{|c|}{249.5} & \multicolumn{2}{|c|}{219.4} \\
\hline AMSR-E A & \multicolumn{2}{|c|}{253.2} & \multicolumn{2}{|c|}{230.2} \\
\hline $\mathrm{SSM} / \mathrm{I} \mathrm{D}$ & \multicolumn{2}{|c|}{249.2} & \multicolumn{2}{|c|}{223.9} \\
\hline
\end{tabular}

${ }^{\text {a }}$ The values of brightness temperatures observed from AMSR-E and SSM/I satellite radiometers are also reported. 
the resolutions coarser than $5000 \mathrm{~m}$, the histograms are relatively uniform.

[11] We compare the values of brightness temperatures obtained by re-sampling the PSR-A data at $25 \mathrm{~km}$ resolution with those recorded by the SSM/I and AMSR-E. In general, the values recorded by the space-borne instruments are consistent with those obtained from averaging the PSR/A data. The observed differences between airborne and satellite data can be partly due to the atmospheric correction applied to the two data sets, to terrain topography and to the different times at which the data were acquired. The PSR/A flew over the areas around 20:30 UTC time while the AMSR-E passed over at 19:54 UTC time (ascending orbit) and 8:49 UTC (descending orbit). The SSM/I passed over at 14:18 UTC time (descending orbit). No coverage was available for the SSM/I on its ascending orbit. In the case of the Fraser MSA, we observe that the brightness temperatures recorded by AMSR-E and SSM/I differ at maximum by $3.5 \mathrm{~K}$ from those obtained by averaging the PSR/A data to $25 \mathrm{~km}$ resolution, except for the observation from the $\mathrm{SSM} / \mathrm{I}$ descending overpass at $37 \mathrm{GHz}$, which is $7.9 \mathrm{~K}$ lower than that of the PSR/A. This could be due to the fact that the SSM/I descending overflight occurred at night, when surface temperatures were decidedly cooler. Also in the case of the North Park MSA, the brightness temperatures recorded by the AMSR-E and SSM/I are consistent with those obtained by averaging the PSR/A data. In this case the best match is obtained in the case of the SSM/I descending overflight and the maximum error is obtained in the case of the AMSR-E ascending overflight at $37 \mathrm{GHz}$. The differences observed between the averaged PSR/A brightness temperatures and space-borne radiometric data can be due to the size of the surface footprint of the AMSR-E and SSM/I, the position of the center of the surface footprints and different calibration/validation procedures.

\section{Conclusions}

[12] The brightness temperatures collected using the high-resolution airborne NOAA Polarimetric Scanning Radiometer during the Cold Land Processes Experiment-1 have been aggregated to simulate coarser resolutions. Histograms of the PSR/A brightness temperatures at finest resolution $(500 \mathrm{~m})$ display a log-normal distribution in the case of the Fraser forested area and a bi-modal distribution in the case of the patchy-snow non-forested North Park area. The histograms of brightness temperatures at successively coarser resolutions have been studied to understand the effect of the pixel size on the shape of the distribution. For all examined cases, a threshold value of $5000 \mathrm{~m}$ resolution has been found after which the histograms of the brightness temperatures become relatively uniform (all brightness temperatures have the same number of occurrences). The values of the brightness temperatures obtained by aggregating the PSR/A data to a $25 \mathrm{~km}$ resolution have been compared with the values of the brightness temperatures collected by the AMSR-E and SSM/I radiometers and were found to be within $7.7 \mathrm{~K}$ in the case of the Fraser area and $7.1 \mathrm{~K}$ in the case of the North Park area. In future studies, we will use the data collected during the Cold Land
Processes Experiment during March 2002 and 2003 in order to extend the study to wet snow conditions.

[13] Acknowledgments. We would like to thank Richard Armstrong and Mary Brodzik from the National Snow and Ice Data Center, Boulder, $\mathrm{CO}$, for providing the SSM/I and AMSR-E brightness temperatures. We also would like to thank Richard Kelly for the constructive discussions and valuable assistance provided during the study.

\section{References}

Brodzik, M. J. (Ed.) (2003a), CLPX-Satellite: AMSR-E Brightness Temperature Grids, http://nsidc.org/data/nsidc-0145.html, Natl. Snow and Ice Data Cent., Boulder, Colo.

Brodzik, M. J. (Ed.) (2003b), CLPX-satellite: SSM/I brightness temperature grids, http://nsidc.org/data/nsidc-0144.html, Natl. Snow and Ice Data Cent., Boulder, Colo.

Derksen, C., A. Walker, B. Goodison, and J. W. Strapp (2005), Integrating in situ and multiscale passive microwave data for estimation of sub-grid scale snow water equivalent distribution and variability, IEEE Trans. Geosci. Remote Sens., 43, 960-972.

Drusch, M., E. Wood, and C. Simmer (1999), Up-scaling effects in passive microwave remote sensing: ESTAR $1.4 \mathrm{GHz}$ measurements during SGP'97, Geophys. Res. Lett., 26, 879-882.

Famiglietti, J., J. Devereaux, C. Laymon, T. Tsegaye, P. Houser, T. Jackson, S. Graham, M. Rodell, and P. van Oeleven (1999), Ground-based investigation of soil moisture variability within remote sensing footprints during the Southern Great Plains 1997 (SGP97) Hydrology Experiment, Water Resour. Res., 35, 1839-1851.

Foster, J., A. Chang, and D. Hall (1997), Comparison of snow mass estimates from a prototype passive microwave snow algorithm, a revised algorithm and a snow depth climatology, Remote Sens. Environ., 62, $132-142$.

Hallikainen, M., and P. Jolma (1992), Comparison of algorithms for the retrieval of snow water equivalent from NIMBUS-7 SMMR data in Finland, IEEE Trans. Geosci. Remote Sens., 30, 124-131.

Jackson, T. (2001), Multiple resolution analysis of L-band brightness temperature for soil moisture, IEEE Trans. Geosci. Remote Sens., 39, $151-164$.

Kelly, R. E., A. T. Chang, L. Tsang, and J. Foster (2003), A prototype AMSR-E global snow area and snow depth algorithm, IEEE Trans. Geosci. Remote Sens., 41, 230-242.

Macelloni, G., S. Paloscia, P. Pampaloni, and M. Tedesco (2001), Microwave emission from dry snow: A comparison of experimental and model result, IEEE Trans. Geosci. Remote Sens., 39, 2649-2656.

Piepmeier, J. R., and A. J. Gasiewski (1996), Polarimetric scanning radiometer for airborne microwave imaging studies, in IGARSS '96: 1996 International Geoscience and Remote Sensing Symposium: Remote Sensing for a Sustainable Future, vol. 2, edited by T. Stein and J. Brunk, pp. 1120-1122, Inst. of Electr. and Electr. Eng., New York.

Robinson, D., K. Dewey, and R. Heim (1993), Global snow cover monitoring: An update, Bull. Am. Meteorol. Soc., 74, 1689-1696.

Stankov, B., and A. Gasiewski (2004), CLPX-Airborne: Multiband Polarimetric Scanning Radiometer (PSR) Imagery. Boulder, http://nsidc.org/ data/nsidc-0155.html, Natl. Snow and Ice Data Cent., Boulder, Colo.

Tait, A. (1998), Estimation of snow water equivalent using passive microwave radiation data, Remote Sens. Environ., 64, 286-291.

Tedesco, M. (2003), Microwave remote sensing of snow, Ph.D. thesis, Inst. of Appl. Phys. "Nello Carrara," Ital. Natl. Res. Counc., Florence, Italy. Tedesco, M., J. Pulliainen, P. Pampaloni, and M. Hallikainen (2004a), Artificial neural network based techniques for the retrieval of SWE and snow depth from SSM/I data, Remote Sens Environ., 90, 76-85.

Tedesco, M., E. J. Kim, D. Cline, T. Graf, T. Koike, R. Armstrong, M. Brodzik, B. Stankov, A. Gasiewski, and M. Klein (2004b), Exploring scaling issues by using NASA Cold Land Processes Experiment (CLPX-1, IOP3) radiometric data, in Geoscience and Remote Sensing Symposium, 2004: IGARSS '04, vol. 3, pp. 1657-1660, Inst. of Electr. and Electr. Eng., New York.

A. Gasiewski, M. Klein, and B. Stankov, NOAA Environmental Technology Laboratory, 325 Broadway R/ETL, Boulder, CO 803053328, USA.

E. J. Kim, Instrumentation Sciences Branch, NASA GSFC, Code 614.6, Greenbelt, MD 20771, USA.

M. Tedesco, Goddard Earth Science Technology Center, UMBC/NASA GSFC, Code 614.6, Greenbelt, MD 20771, USA. (mtedesco@umbc.edu) 